\title{
Estudantes das camadas populares no ensino superior público: qual a contribuição da escola?
}

\author{
Débora Cristina Piotto \\ Renata Oliveira Alves
}

\begin{abstract}
Resumo
Os estudos sobre o fracasso escolar que partem de uma concepção crítica da relação entre escola e sociedade e discutem a participação da escola em sua produção são mais numerosos do que pesquisas sobre o sucesso escolar que partem de tal perspectiva. Alguns estudos brasileiros se dedicaram a pesquisar trajetórias escolares bem-sucedidas, porém seus focos de investigação foram as práticas educativas familiares. Assim, o objetivo do presente trabalho é discutir algumas questões relativas à participação da escola na construção de trajetórias escolares prolongadas nas camadas populares. Para isso, analisamos aspectos de entrevistas em profundidade realizadas com duas estudantes de Pedagogia de uma universidade pública provenientes das camadas populares. Com base nas contribuições de estudos sobre o tema, bem como em alguns conceitos da teoria histórico-cultural, discutimos como a escola esteve presente na construção das trajetórias analisadas.
\end{abstract}

Palavras-chave: Ensino superior, famílias de baixa renda, rendimento escolar.

\section{Lower classes students in public universities: what is the school's contribution?}

\begin{abstract}
Works on school failure, with a critical comprehension of the relationship between school and society, are more frequent than works on school success. Some Brazilian scholars have investigated well succeeded scholar trajectories, but their focus were on the family educative practices. The aim of this article is to discuss questions related to the participation of school in extended scholar trajectories in lower classes. In order to reach this goal, we will analyze some features of two interviews carried out with two low-class students of Pedagogy of a public university. Supported by some studies in the area, as well as based on some concepts of historical-cultural theory, we discuss how school was present in the construction of the analyzed trajectories.
\end{abstract}

Keywords: Higher education, low income families, academic achievement.

\section{Estudiantes de clases populares en la enseñanza superior pública: cuál es}

\section{la contribución de la escuela?}

\section{Resumen}

Los estudios sobre el fracaso escolar que parten de una concepción crítica de la relación entre escuela y sociedad y que discuten la participación de la escuela en su producción son más numerosos que investigaciones sobre el éxito escolar a partir de dicha perspectiva. Algunos estudios brasileños se dedicaron a investigar trayectorias escolares exitosas, sin embargo sus focos de investigación fueron las prácticas educativas familiares. Por lo tanto, el objetivo del presente trabajo es discutir algunas cuestiones relativas a la participación de la escuela en la construcción de trayectorias escolares prolongadas en las clases populares. Con esta finalidad analizamos aspectos de entrevistas en profundidad realizadas con dos estudiantes de Pedagogía de una universidad pública, provenientes de clases populares. Con base en las contribuciones de estudios sobre el tema, así como en algunos conceptos de la teoría histórico-cultural, discutimos como la escuela estuvo presente en la construcción de las trayectorias analizadas.

Palabras Clave: Educación superior, familias de bajos recursos, rendimiento escolar. 


\section{Introdução}

A partir do início dos anos 1980, começam a surgir no Brasil estudos que modificaram a forma por meio da qual se entendia o fenômeno do fracasso escolar, ao abandonarem uma concepção que responsabilizava predominantemente o aluno e sua família e buscarem uma compreensão crítica da relação entre escola e sociedade, investigando processos e práticas escolares cotidianos e discutindo a participação da escola na produção do fracasso escolar. Como exemplos de pesquisas precursoras, podemos citar os trabalhos de Campos (1984), Campos e Goldenstein (1981), Goldenstein (1986), Patto (1990) e Spósito (1984), entre outras.

Por outro lado, o tema do sucesso escolar tem sido pouco investigado em nossa realidade. Alguns trabalhos, como os de Portes (2001), Setton (1999) e Viana (1998) apontam os parcos conhecimentos existentes a respeito e a necessidade de novas investigações.

$\mathrm{Na}$ literatura científica de língua estrangeira, uma pesquisa que se dedicou ao tema foi a realizada por Lahire (1997). O autor investigou as relações entre as posições escolares e as configurações familiares de crianças provenientes de camadas populares que frequentavam a $2^{a}$ série do correspondente ao Ensino Fundamental na França. Nos perfis descritos, há casos que vão desde "fracassos" previsíveis, passando por histórias de "fracassos" improváveis, até os casos de "sucessos" brilhantes.

Nesse trabalho, Lahire (1997) discute a relação entre as configurações familiares de cada criança e o mundo escolar. Se, por exemplo, algumas das histórias de "sucessos" escolares improváveis encontradas não podem ser explicadas por meio das práticas de leitura, escrita ou de organização das atividades domésticas das famílias, o autor procura-as nas relações entre pais e filhos, principalmente no tocante às atividades escolares. Assim, para Lahire, são as características da organização familiar que explicam trajetórias escolares bem-sucedidas, na inexistência - total ou parcial - de capital cultural. E, mesmo quando este capital existir, para sua apropriação, são necessárias interações efetivas e afetivas. Isto é, não basta a escolarização do pai ou da mãe, é preciso que o detentor desse capital escolar esteja disponível, tanto objetiva quanto subjetivamente, de forma a possibilitar as adequadas condições para que o capital possa ser herdado.

Nos perfis descritos por Lahire (1997), destaca-se a riqueza das informações acerca das realidades objetivas e subjetivas vividas pelas famílias entrevistadas. Todavia, apesar de também terem sido feitas entrevistas com os professores das crianças, muito pouco sabemos sobre a escola.

De fato, o interesse específico de Lahire na investigação empreendida foi a relação das famílias de camadas populares com situações de sucesso e de fracasso escolares. Ainda assim, chama a atenção a ausência da escola na análise realizada. A compreensão a respeito da participação da escola nas questões abordadas é explicitada, ao menos em parte, nas conclusões em uma nota de rodapé:
É preciso acrescentar que, se nossa pesquisa tem como objetivo as dissonâncias e as consonâncias entre socialização escolar e socialização familiar, acentuando as especificidades, as pressões próprias das configurações familiares, a escola também participa, sem dúvida, da produção de alguns mal-entendidos prejudiciais à escolaridade das crianças... (Lahire, 1997, p. 354).

Como exemplo de um "mal-entendido", o autor cita o tempo de horário livre em que muitas crianças permanecem na escola após as aulas para realizarem as tarefas. Por confiarem "cegamente" na instituição escolar, os pais não verificam, eles próprios, os cadernos dos filhos, acreditando estarem as lições completas e corretas, já que as crianças teriam sido ajudadas por profissionais competentes, o que nem sempre ocorre.

A referência a uma pesquisa situada no contexto do sistema de ensino francês não desconsidera as diferenças que o separam da realidade da educação pública brasileira. Entretanto, como já amplamente discutido na literatura educacional de nosso país - ver, por exemplo, os trabalhos de Collares e Moysés (1996), Cruz (1997), Paro (1995), Patto (1990), Sawaya (1999) e Spósito (1993) entre vários outros -, a escola parece ter maior participação na produção do fracasso escolar do que a contribuição com "mal-entendidos" como a citada.

Partindo dos pressupostos teórico-metodológicos de Lahire (1997), duas pesquisas investigaram o tema da longevidade escolar ${ }^{1}$ nas camadas populares em nossa realidade. Vejamos se e como a instituição escolar comparece nesses trabalhos.

Um dos estudos é o de Viana (2000), que entrevistou sete estudantes que ingressaram no Ensino Superior provenientes de famílias com dificuldades econômicas, baixo nível de escolaridade e pais exercendo trabalhos predominantemente manuais.

Analisando essas biografias escolares, a autora trata do papel das diferentes esferas presentes na configuração das trajetórias analisadas: a família, o filho-aluno e a escola, entendidas como âmbitos interdependentes. Todavia, embora reconheça que aspectos ligados à instituição escolar e seu funcionamento estejam relacionados com as trajetórias pesquisadas, a autora esclarece que, em seu estudo, a escola aparece apenas de maneira indireta como "figura importante de bastidores".

De fato, na análise realizada por Viana (2000), a escola assume importante papel quando a autora aponta, por exemplo, a centralidade do êxito nas primeiras séries do

\footnotetext{
1 Por longevidade escolar, entendemos a permanência no sistema de ensino até o Ensino Superior. Utilizamos esse termo, bem como o de "trajetórias escolares prolongadas", por se tratarem de expressões já consolidadas na Sociologia da Educação, área que tem se dedicado ao estudo do tema. Ao se referir a um prolongamento, tais termos também retratam os dados existentes que mostram que é (ainda) muito pequeno o número de estudantes das camadas populares no Ensino Superior. Reconhecemos, no entanto, que o acesso e a permanência desses estudantes nesse nível de ensino são um direito.
} 
Ensino Fundamental para o início da construção de uma trajetória escolar bem-sucedida. Ou ainda quando afirma que a autodeterminação observada em seus entrevistados fora construída ao longo do processo de escolarização.

Entretanto, apesar desse destacado papel, a escola não se torna objeto de maiores reflexões, tendo em vista não ter sido esse o objetivo da pesquisa.

Outro estudo que investiga a relação entre longevidade escolar e camadas populares é o de Portes (2000). Esse pesquisador entrevistou seis jovens provenientes de famílias das camadas populares e alunos das carreiras mais concorridas da UFMG.

Ao discutir o trabalho escolar realizado pelas famílias das camadas populares que, de alguma forma, contribuiu para o acesso dos filhos à universidade pública em cursos altamente valorizados socialmente, o autor afirma que esse trabalho ganha sentido através de uma série de ações que compõem um "conjunto de circunstâncias atuantes". Dentre essas circunstâncias, pelo menos uma refere-se explicitamente à escola - a presença do outro na vida do estudante -, já que este outro é, nas histórias descritas, sempre um professor $^{2}$. A percepção por parte de determinados professores do bom desempenho escolar, por exemplo, parece ser determinante na vida dos estudantes entrevistados, possuindo importante papel na construção de uma "lógica do sucesso" (Accardo, 1997).

A "eterna aproximação dos professores" (Portes, 2000) é outro aspecto importante nas trajetórias escolares analisadas. Através do reconhecimento e do incentivo à dedicação, ao esforço e ao desempenho acadêmico, o professor contribui para a construção da autonomia, segurança e autoestima desses estudantes.

Como na pesquisa realizada por Viana (2000), no estudo de Portes (2000), a escola esteve presente em momentos importantes nas trajetórias analisadas, apesar de não ter se constituído foco da investigação.

Uma pesquisa que nos ajuda a pensar sobre a contribuição da escola para casos de trajetórias escolares bem-sucedidas em meios populares é a realizada por Rochex (1995). Com o objetivo de melhor compreender o sentido da experiência escolar, esse autor entrevistou dez adolescentes filhos de imigrantes residentes na França que possuíam três diferentes tipos de vivências escolares: alguns com sucesso escolar brilhante, outros com situação escolar problemática do ponto de vista da aprendizagem e um terceiro grupo de adolescentes que apresentava problemas de comportamento na escola. Para o presente trabalho, interessa-nos, sobretudo, o primeiro tipo de experiência escolar.

Rochex (1995) relaciona os casos, por ele denominados, de "sucesso escolar" a determinados sentidos atribuídos à escolarização, bem como a determinados tipos de relação dos adolescentes com suas origens sociais, representadas principalmente por suas famílias.

Segundo o autor, o sentido da experiência escolar pode ser definido basicamente por duas dimensões - uma

2 Com exceção de um caso. objetiva e outra subjetiva. A primeira diz respeito à escola, afirmando Rochex (1995) que, para os adolescentes entrevistados que possuíam uma trajetória escolar bem-sucedida, as atividades e os conteúdos escolares tinham valor neles mesmos, além de terem significado por seus valores cognitivos, intelectuais, estéticos e de ampliação de conhecimentos. Para esses adolescentes, a escola não era concebida como concorrente ou antagônica à família; o universo escolar era entendido em sua especificidade, com uma "normatividade" que o diferenciava do universo familiar e o fazia ultrapassar as relações interpessoais.

A dimensão subjetiva, por sua vez, está relacionada à noção de tríplice autorização. Para Rochex (1995), a emancipação da herança familiar, ou seja, a não reprodução da história escolar e social da família por parte dos filhos é possível a partir de três tipos de autorizações. Uma delas refere-se à autorização do próprio filho-estudante para "deixar" a família, empreendendo um movimento de emancipação, sem reproduzir a história familiar. A outra autorização diz respeito aos pais que autorizam o filho a se emancipar, a ser outro, com uma história diferente da deles. E a terceira consiste em uma autorização recíproca, a partir da qual há um reconhecimento mútuo entre pais e filhos de que a história de cada um é legítima sem ser a sua própria.

Mas, se a relação dos adolescentes com suas origens sociais é importante fonte de mobilização escolar, também a escola contribui para essa relação. Segundo Rochex (1995), a emancipação simbólica, autorizada dentro do espaço familiar, é estruturada e reforçada por conteúdos escolares significativos.

Partindo dessa discussão e das contribuições dos estudos sobre estudantes das camadas populares no Ensino Superior brasileiro, o objetivo do presente trabalho é discutir algumas questões relativas à participação da escola na construção de trajetórias escolares prolongadas nas camadas populares.

Para isso, analisará aspectos de entrevistas em profundidade realizadas com duas estudantes do Ensino Superior público provenientes de camadas populares, as quais têm a educação como objeto de estudo e futuro campo de atuação, isto é, alunas do curso de Pedagogia de uma importante universidade pública.

Estudantes desse curso foram escolhidas por julgarmos que possuíssem, além de vivências escolares próprias, reflexões sobre a estrutura e o funcionamento escolares. As duas alunas entrevistadas cursavam o sétimo semestre do curso de Pedagogia no período noturno. A escolha das estudantes considerou a origem social familiar - cujos critérios para definição foram grau de escolaridade e ocupação dos pais e renda familiar - e a proximidade social e familiaridade com a entrevistadora, colega de turma das estudantes, por acreditarmos, com Bourdieu (1997), que esse fato permite entrevistas de maior profundidade.

O conteúdo das entrevistas versou sobre a vida escolar das entrevistadas, suas percepções e lembranças de professores, entre outros aspectos. A realização das entrevistas teve como apoio o trabalho de Bosi $(1979,1993)$, bem 
como as contribuições teórico-metodológicas de Gonçalves Filho (2003).

\section{Bem comportadas e afeitas à leitura: duas alunas perfeitas}

As duas estudantes entrevistadas possuem em comum a origem nordestina, as dificuldades financeiras da família, a conciliação entre trabalho e estudo e o fato de sempre terem sido boas alunas.

Juliana, 31 anos, trabalha como professora da Educação Infantil na rede municipal. Seu pai, analfabeto, migrou com a família da Bahia para São Paulo a fim de trabalhar no corte da cana, em virtude das sérias dificuldades enfrentadas naquele Estado (a situação econômica familiar era bastante precária, sendo que, por vezes, chegavam a se alimentar de palma - planta comum na região Nordeste, geralmente utilizada para a alimentação do gado - e banana verde cozida para não passarem fome). Sua mãe cursou até a quarta série do Ensino Fundamental e também passou a trabalhar no corte da cana ao chegar a São Paulo. Ela possui oito irmãos, dos quais apenas a mais nova concluiu o Ensino Médio, enquanto os demais não terminaram o Ensino Fundamental.

A estudante ingressou na escola aos nove anos idade quando a família mudou-se para o interior paulista e, apesar de ter conciliado trabalho e estudo desde os dez anos, ao começar a trabalhar como empregada doméstica e posteriormente também como babá, Juliana sempre apresentou bom rendimento escolar. Insatisfeita com o desrespeito e a exploração a que era submetida nos empregos, Juliana resolveu, ao final do Ensino Fundamental, cursar Magistério, pois tal curso só era oferecido no período matutino - o que, na visão da estudante, diminuiria as chances de que alguém a contratasse como empregada doméstica. No entanto, dada a situação econômica familiar, ela foi obrigada a voltar a trabalhar, mas, desta feita, apenas no período da tarde e três vezes por semana. Juliana, no entanto, continuou sendo boa aluna e seu ótimo desempenho no Magistério foi premiado com uma inscrição gratuita para o vestibular da Universidade do Estado de São Paulo - UNESP, onde prestou Letras e ficou na lista de espera. Todavia, como não sabia que deveria manifestar oficialmente o interesse pela vaga, nunca foi chamada e, assim, continuou trabalhando como doméstica por vários anos. Trabalhou também em uma padaria e na linha de produção de uma grande indústria de bebidas, trabalho que ainda exercia quando ingressou na universidade.

$\mathrm{Na}$ tentativa de conseguir um emprego mais bem remunerado que the possibilitasse o pagamento das mensalidades de uma faculdade particular, essa estudante fez vários cursos técnicos. Durante um deles, Juliana conheceu um rapaz com o qual passou a cogitar a possibilidade de ingressarem em uma universidade pública, decidindo fazer um curso preparatório gratuito para o vestibular. Embora considere que as aulas no "cursinho" não foram suficientes para corrigir o grande déficit que apresentava nos conteúdos de algumas disciplinas, Juliana atribui grande importância ao material didático recebido e às informações fornecidas acerca das universidades e dos vestibulares. Ela foi aprovada nos vestibulares de duas universidades públicas: novamente no da UNESP e no exame da universidade onde estuda atualmente.

Luciene, 33 anos, casada, trabalha como secretária na universidade onde também estuda. Seu pai, vigia aposentado, morou durante onze anos em um seminário, onde realizou seus estudos de modo "informal", e sua mãe, dona de casa, estudou até a $3^{a}$ série do Ensino Fundamental; ambos são originários do interior do Estado do Ceará. Luciene possui três irmãos: um de 36 anos, que concluiu o Ensino Médio na modalidade de ensino supletivo e trabalha como porteiro, outro de 34 anos, que cursou até a $7^{a}$ série do Ensino Fundamental e é vendedor ambulante e o caçula, de 24 anos, que cursa Educação Física em uma faculdade particular, mas cuja matrícula estava trancada em virtude de dificuldades com o pagamento das mensalidades.

Luciene começou a frequentar a escola aos quatro anos de idade quando sua mãe conseguiu um emprego e, ao não ter com quem deixá-la, obteve a autorização da diretora para que ela permanecesse, junto com os irmãos, o dia todo na escola, mesmo sendo o atendimento apenas a crianças de seis anos ou mais. Tendo se alfabetizado na pré-escola, era destaque na escola para onde, por conta da mudança da família, foi transferida na segunda série e na qual muitos colegas ainda não sabiam ler e escrever. Contrastando com o seu bom desempenho escolar, Luciene tinha dificuldades com a disciplina de Matemática e, após ter ficado de recuperação na matéria na sétima série, optou por não fazer a avaliação final, de maneira que fosse reprovada para que, no próximo ano, pudesse tentar novamente aprender o conteúdo. Na busca de uma educação de melhor qualidade, Luciene transferiu-se duas vezes para escolas localizadas na região central da cidade onde residia. A partir da oitava série, passou a frequentar a escola no período noturno. Durante o primeiro ano do Ensino Médio, começou a trabalhar durante meio período em uma grande rede de lanchonetes. Já no segundo ano, passou a trabalhar oito horas diárias como caixa em um supermercado. Todavia, nesse ano, seu pai adoeceu e, diante da sua impossibilidade de trabalhar, Luciene pediu demissão e usou o seu FGTS e o seguro desemprego para ajudar a família, que passava por sérias dificuldades econômicas. Posteriormente, voltou a trabalhar em uma indústria de produtos odontológicos, mas, após ser demitida e não conseguir encontrar um novo emprego, matriculou-se em um curso de Secretariado, conquistando, após uma seleção, uma vaga de estágio na empresa de telefonia da cidade. Com a privatização da empresa e o fim do estágio, Luciene viu-se novamente desempregada, situação que mudou quando a estudante prestou concurso e foi aprovada para trabalhar em uma universidade pública, o que lhe despertou a ideia de também cursar uma faculdade naquele local. Nos dois primeiros anos em que prestou o vestibular, a estudante tentou ingressar no curso de Biblioteconomia e, depois, mudou sua opção para Pedagogia, mas também não conseguiu a aprovação. Em todas essas ocasiões, sem- 
pre faltavam poucos pontos para a sua aprovação, pontos esses, em geral, localizados na área de Exatas, sua grande dificuldade. Essa situação fez com que a estudante recorresse a um curso preparatório semi-intensivo para o vestibular na intenção de melhorar seu desempenho nessa área, o que, segundo Luciene, não se concretizou. Não obstante, foi neste ano que conseguiu ser aprovada no vestibular para o curso de Pedagogia, ficando na lista de espera e sendo chamada após algum tempo.

Os relatos de Juliana e Luciene, no tocante ao comportamento e às atividades escolares, indicam que suas posturas no interior da escola eram bastante semelhantes, sobretudo no início da escolarização. A presteza e o prazer em realizar as atividades propostas pelas professoras, bem como o fato de serem alunas muito disciplinadas e obedientes faziam com que fossem consideradas, pelos seus professores, boas alunas. O temperamento dócil de Juliana também era uma característica que a distinguia dos demais alunos da turma, o que, segundo ela, fazia com que os professores lhe dispensassem um tratamento diferenciado. Sua dedicação aos estudos também Ihe rendia a atenção e a preocupação dos professores com o seu aprendizado, já que, no início de sua escolarização, fizeram questão de que Juliana estivesse sempre frequentando as salas mais adiantadas, tendo a chance de aprender cada vez mais. Também Luciene lembra, por exemplo, que seu caderno era caprichado, que fazia todas as lições, apresentando um bom rendimento escolar e, além disso, era muito comportada, de modo que os professores a viam como uma aluna "perfeita".

O apreço pela leitura também se destaca nos relatos das duas estudantes. Juliana ansiava por aprender a ler e, quando conseguiu fazê-lo, ficou muito entusiasmada com essa conquista. A estudante afirma que ficou "apaixonada" pela leitura e desejava sempre ler e mostrar às pessoas à sua volta o seu aprendizado. Os livros foram, para Juliana, uma grande fonte de prazer, maior até que, afirma ela, a televisão e as brincadeiras com os amigos. Além disso, a estudante faz referência especial a alguns livros, indicando que a leitura foi uma companheira importante até mesmo para auxiliá-la a lidar com os conflitos próprios da adolescência. A estudante lembra que era frequentadora assídua da biblioteca da escola, emprestando todos os livros que despertavam seu interesse. Outrossim, Luciene também revela o significado que teve o aprendizado da leitura em sua trajetória escolar. A estudante, que, como vimos, começou a frequentar a escola aos quatro anos, algo incomum para a época, aprendeu a ler antes mesmo de ingressar na primeira série do Ensino Fundamental e relata que lia vorazmente os livros fornecidos pela escola. Em razão da alegada timidez e dificuldade de fazer amigos, era no mundo da leitura que Luciene encontrava entretenimento: até mesmo na hora do recreio, era à biblioteca da escola que a estudante se dirigia e lá permanecia lendo até a hora de voltar para a sala de aula. Quando soube que os livros poderiam ser levados para casa, passou a ser uma usuária ainda mais constante daquele espaço.
Foi também o aprendizado da leitura e da escrita que possibilitou o desenvolvimento de certo autodidatismo, de grande importância na trajetória das duas entrevistadas. Devido à qualidade precária do ensino nas escolas públicas que frequentou, Juliana dependia da sua habilidade de leitura para tentar compreender determinadas matérias. Assim, na falta de bons professores, ela recorria aos livros para adquirir o conhecimento que os mestres não proporcionavam. Essa importância da leitura mostrou-se ainda mais relevante durante o período em que a estudante estava tentando ingressar na universidade. Ao começar a frequentar o curso preparatório para o vestibular, ela percebera as lacunas deixadas pela baixa qualidade do ensino recebido por ela. Além disso, por ter cursado o Magistério, havia matérias que ela nunca tinha estudado e era lendo as apostilas fornecidas pelo "cursinho" que Juliana conseguia aprender um pouco mais. Já no interior da universidade, a estudante deparou-se com as leituras acadêmicas, que julgava "pesadas demais". Ela avalia que foi devido aos seus hábitos de leitura que conseguiu superar as dificuldades iniciais em relação aos textos acadêmicos e, assim, passar a ter maior compreensão dos assuntos tratados naqueles textos.

Também Luciene, durante sua educação básica, quando tinha dúvidas em relação a alguma matéria, era aos livros que recorria para esclarecê-las, uma vez que, de acordo com ela, tinha dificuldades em se aproximar da maioria de seus professores. Ao concluir o Ensino Médio, embora não tivesse a intenção de dar continuidade à sua escolarização, Luciene continuava estudando em casa, lendo sobre os assuntos que mais lhe agradavam. Embora esses estudos não Ihe conferissem nenhuma certificação, a estudante afirma que foram essas leituras que a diferenciaram dos demais candidatos à vaga de estágio em uma empresa de telefonia quando ela voltara a estudar, cursando Secretariado. A afinidade com a leitura mostrou-se novamente relevante quando a estudante estava tentando ingressar na universidade, ocasião em que estudava em casa, lendo apostilas que adquirira em lojas de livros usados. Também na universidade, suas habilidades de leitura e escrita fizeram com que Luciene tivesse um bom desempenho no curso de Pedagogia, destacando-se em avaliações e trabalhos acadêmicos.

Além do aprendizado da leitura e da escrita e do acesso aos livros, destaca-se a pequena referência a professores que marcaram as trajetórias escolares de Juliana e Luciene.

No relato de Juliana sobre seus doze anos de escolarização, apenas a figura de uma professora do primeiro ano do Ensino Médio sobressaiu-se. Luciene, por sua vez, durante os aproximadamente quinze anos em que concluiu a educação básica, guardou consigo a lembrança de duas professoras: uma da pré-escola e outra da quinta série. Em ambos os casos a experiência é relatada como tendo sido marcante e positiva.

Juliana demonstrou, ao contar sua trajetória escolar, grande apreço e admiração por sua professora de História do Ensino Médio. Para a estudante, aquela profissional representou um exemplo de compromisso com a docência, de 
conhecimento da área e também da forma como conduzir as aulas. A estudante relata que suas aulas eram tão ricas e prazerosas que, quando havia avaliação, nem mesmo sentia necessidade de estudar para a prova.

Já no caso de Luciene, um ano de convivência com uma professora da pré-escola foi suficiente para que se lembrasse dela com carinho, recordando inclusive palavras ditas pela docente 26 anos atrás. Da mesma forma, a professora de Ciências na quinta série permaneceu na memória dessa estudante como uma figura emblemática de profissionalismo e envolvimento com o trabalho pedagógico, sendo até mesmo apontada pela aluna como possível inspiração para o seu desejo de se tornar professora.

Todavia, não obstante essas boas recordações, lembranças negativas de professores estiveram mais presentes nas falas de Juliana e Luciene do que as positivas, fato evidenciado quando expuseram suas concepções acerca da escola, sobre a qual revelaram uma postura bastante crítica.

\section{As futuras pedagogas e a escola}

Juliana e Luciene possuem uma visão diferenciada em relação à escola e demonstram um olhar bastante crítico acerca de sua estrutura e seu funcionamento. Ao rememorarem suas trajetórias escolares, o fizeram não só como estudantes que já foram e que ainda são, mas também sob a ótica de futuras pedagogas.

No relato de Juliana, a escola é alvo de várias críticas. Uma dessas críticas, por exemplo, está relacionada ao que ela entende como um investimento, realizado pelos professores, nos alunos que possuem bom desempenho, em detrimento daqueles que apresentam dificuldades no seu aprendizado. Para ilustrar sua afirmação, ela cita os presentes oferecidos aos bons alunos, como os que recebia, a preocupação dos professores em mantê-la sempre nas classes mais adiantadas e o tratamento desigual dispensado aos considerados bons e maus alunos. Para a estudante, essa dinâmica escolar exerce uma seleção que privilegia aqueles que já têm bons rendimentos escolares, deixando em desvantagem os demais alunos.

Outrossim, Luciene também tece críticas à instituição escolar. Um dos principais alvos é a falta de compromisso dos professores com o aprendizado do aluno, que ela aponta como intensificador das dificuldades enfrentadas por alguns estudantes, pelos quais, muitas vezes, os docentes não se interessam. O ensino no curso de Secretariado, por sua vez, foi avaliado pela estudante como fortemente tecnicista, voltado exclusivamente ao ensino das habilidades profissionais, em detrimento de uma formação em outras dimensões do conhecimento, como a Literatura. O curso preparatório para o vestibular é visto como voltado apenas a ensinar ao aluno como ser aprovado nesse exame.

No cerne das recordações escolares de Juliana e de Luciene, bem como da concepção a respeito da escola, parece-nos que estão as dificuldades enfrentadas por essas estudantes, frutos da precária qualidade do ensino a que tiveram acesso.
Partindo dessas experiências e retomando o objetivo do presente trabalho, perguntamo-nos: é possível pensar a participação da escola na construção de trajetórias como as de Juliana e Luciene?

Para discutir as funções social e simbólica da escola e seu papel na construção de trajetórias escolares bem-sucedidas nas camadas populares, Rochex (1995) vale-se das contribuições de alguns teóricos da área da Psicologia, como Vigotski (1984). Nessa mesma direção, procuraremos discutir em que medida algumas das ideias desse autor podem nos ajudar a pensar sobre a contribuição da escola para a construção de trajetórias escolares prolongadas nas camadas populares.

\section{A contribuição da escola na teoria histórico-cultural}

A partir da maneira como a teoria histórico-cultural concebe a relação entre aprendizagem e desenvolvimento pode-se compreender o lugar de destaque que a escola possui nessa teoria. Vigotski (1984) afirma que a aprendizagem precede e impulsiona o desenvolvimento; isto significa dizer que os processos de aprendizado movimentam os processos de desenvolvimento. Estreitamente relacionado a essa forma de conceber tal relação, está o conceito de zona de Desenvolvimento Proximal proposto por Vigotski (1984), que representa a distância entre aquilo que a criança é capaz de realizar de maneira autônoma e o que consegue realizar com a colaboração de outrem. É nessa área que, para Vigotski, deve incidir a intervenção pedagógica, já que, para o autor, o bom ensino é aquele que se adianta ao desenvolvimento.

Assim, para a teoria histórico-cultural, a escola - lugar privilegiado e legitimado socialmente onde o processo de ensino-aprendizagem ocorre intencionalmente - é elemento imprescindível, nas sociedades letradas, para o pleno desenvolvimento dos indivíduos (Oliveira, 2005; Rego, 1995). Isso porque, ao proporcionar experiências diferentes daquelas vividas na família, a escola oferece oportunidades de acesso a experiências novas capazes de provocar transformações e promover o desenvolvimento (Rego, 2002). Para isso, concorrem principalmente os procedimentos regulares que têm lugar nessa instituição, como demonstração, assistência e instruções, que constituem aspectos fundamentais para a promoção de um ensino capaz de fazer avançar o desenvolvimento (Oliveira, 2005). Também colabora, para essa promoção, o fato de o saber escolar apresentar descontinuidade em relação ao saber presente em outras esferas da vida cotidiana, como a família, a rua e o trabalho:

O distanciamento dos dados da experiência pessoal, a descontextualização com relação à realidade imediata, o desenvolvimento de procedimentos específicos de reflexão fornecem ao sujeito uma aproximação com a teoria, com a consciência reflexiva (...) que o instrumentalizam para a um trânsito pelo conhecimento que não está balizado por seu valor pragmático, mas por um valor intrínseco (Oliveira (1996, p. 100) 
Esse destacado papel da escola não implica, no entanto, a afirmação de superioridade dos sujeitos escolarizados sobre os não escolarizados. Essa visão dicotômica é superada quando se concebe a escola como espaço privilegiado para formação intelectual dos sujeitos, porém não exclusivo para seu desenvolvimento e sua formação psíquica (Rego, 2002).

Contudo, isso, por sua vez, não significa minimizar a gravidade da exclusão escolar, quer seja pelo não acesso, pelo "abandono", pelo não aprendizado ou pelo aprendizado precário. Ainda que existam outros possíveis caminhos que promovam o desenvolvimento, o acesso a essa instituição, em nossas sociedades, é um direito de todos.

Assumindo a importância da escola para o desenvolvimento psicológico, Rego (2002) realizou uma pesquisa com o objetivo de compreender o impacto da escolarização na constituição psicológica do sujeito, analisando narrativas autobiográficas de seis adultos entre 40 e 50 anos com alto grau de escolaridade, exercendo profissões relacionadas com a produção de conhecimentos e provenientes de famílias de diferentes estratos sociais.

Segundo Rego (2002), um importante aspecto a se analisar para compreender o impacto da escolarização é o próprio contexto escolar. Com base nas premissas vigotskianas do papel central da escola para o desenvolvimento, bem como na compreensão de que, para isso, não é suficiente qualquer escola, a autora afirma a existência de uma íntima relação entre impacto da escolarização e qualidade do trabalho escolar desenvolvido.

$\mathrm{Na}$ pesquisa que a autora realizou, os professores de quem os entrevistados se lembraram foram marcantes porque, de acordo com seus relatos, ensinavam e não subestimavam os alunos. Segundo Rego (2002), ao proceder dessa forma, tais professores agiam sobre a zona de desenvolvimento proximal dos estudantes. Com base nessas recordações, a autora reafirma uma das teses da teoria histórico-cultural: não é qualquer ensino que promove o desenvolvimento. Isso significa dizer que a qualidade da aprendizagem relaciona-se com a qualidade da mediação proporcionada pela escola.

Também as escolas que marcaram os adultos entrevistados por Rego (2002) foram as boas escolas. De forma geral, nos relatos, a maior parte das lembranças escolares está relacionada a boas experiências. Isso permite à autora afirmar que o tipo de trabalho desenvolvido na escola parece ter uma relação direta com as marcas deixadas no sujeito. Assim, as lembranças e a avaliação sobre papel da escola na formação dos indivíduos dependerão da qualidade das experiências vividas. Os entrevistados foram enfáticos ao reconhecer a importância da escola para a constituição de suas singularidades, não apenas no que diz respeito ao desenvolvimento cognitivo, mas também aos aspectos social, cultural, emocional, destacando, no entanto, que tais influências vieram principalmente das experiências escolares mais interessantes.

A consideração da qualidade das experiências escolares para se compreender as lembranças escolares parece fazer bastante sentido no caso dos relatos das estudantes de Pedagogia analisados no presente trabalho. Ao terem tido acesso a uma educação, de forma geral, de baixa qualidade, as lembranças escolares de Juliana e Luciene são mais escassas, as referências a professores são predominantemente negativas e a avaliação da instituição é bastante crítica. Pelo que se pode depreender da discussão feita por Rego (2002), a educação escolar à qual os sujeitos por ela entrevistados tiveram acesso parece ter sido de melhor qualidade do que a recebida pelas estudantes de Pedagogia entrevistadas por nós.

Poderíamos, assim, afirmar que, diferente do que ocorreu nos percursos dos sujeitos entrevistados por Rego (2002), nas trajetórias de Juliana e Luciene, a escola não teve impacto na construção de suas histórias?

Para além do aprendizado da leitura, da escrita e da contagem que essas estudantes só puderam ter acesso via escola, dado o baixo ou inexistente "capital escolar" (Lahire, 1997) de suas famílias, bem como da certificação que Ihes conferiu o direito de alcançar níveis superiores de escolarização, parece-nos que a escola teve outra contribuição na construção das trajetórias das estudantes de Pedagogia.

Oliveira (1996), ao tratar da descontinuidade do saber escolar em relação a outras esferas da vida cotidiana, afirma que o distanciamento e a descontextualização desse saber fornecem subsídios para uma relação com o conhecimento por seu valor intrínseco, o que significa dizer que a validade do saber escolar será dada com base na relação do próprio sujeito com o objeto de conhecimento. E completa a autora:

Nesse sentido é fundamental que a escola forme sujeitos que saibam lidar com ideias, sejam capazes de refletir sobre os objetos de conhecimento e os processos de construção de conhecimento, apreciem o conhecimento como um bem cultural valioso (Oliveira, 1996, p. 100).

Essa nos parece uma contribuição da escola bastante presente nas histórias de Juliana e Luciene. Lembremos, por exemplo, do enorme apreço e interesse que essas duas estudantes relataram ter em relação à leitura e todas as possibilidades que esse aprendizado lhes proporcionou ao longo de suas trajetórias. O gosto, o interesse e a habilidade com a leitura e a escrita foram de grande relevância para que conseguissem preencher algumas das lacunas do ensino a que tiveram acesso; também foram centrais para o desenvolvimento do que chamamos de autodidatismo, uma forma autônoma que essas estudantes desenvolveram de se responsabilizar pela própria formação; foram igualmente importantes para enfrentar as dificuldades do mundo acadêmico com as quais se depararam na universidade; além de terem representado, desde a infância e a adolescência, fontes de prazer, entretenimento e de elaboração de sentimentos. Também a avaliação que as estudantes fizeram dos cursos preparatórios para exames vestibulares, criticando a forma instrumental como lidavam com o conhecimento, bem como do curso de Secretariado como sendo muito tecnicista, nos parece herdeira da capacidade de lidar com 
ideias e refletir sobre objetos de conhecimento, capacidades essas que um sujeito que passe pela escola, segundo Oliveira (1996), deveria ter. Na mesma direção, as várias críticas que as estudantes dirigem à instituição escolar nos parecem vinculadas à capacidade de reflexão, não só sobre o objeto de conhecimento, mas também sobre seus processos de construção e apropriação. E, por fim, a apreciação do conhecimento como um bem cultural valioso e com valor intrínseco parece-nos presente em toda a trajetória social e escolar dessas estudantes, fruto de suas relações com o saber (Charlot, 2000) e coroado no desejo e objetivo de serem professoras.

Em que pese a precariedade da educação escolar recebida por Juliana e Luciene, bem como as críticas feitas por elas à instituição escolar, parece-nos possível afirmar, a partir de seus relatos e das reflexões sobre a função da escola com base na teoria histórico-cultural, que a escola participou da construção de suas trajetórias, contribuindo para o acesso a um lugar socialmente não previsto: o de estudante de uma importante universidade pública.

\section{Referências}

Accardo, A. (1997). Sina escolar. Em P. Bourdieu (Org.), A miséria do mundo (pp. 595-611). Petrópolis, RJ: Vozes.

Bosi, E. (1979). Memória e sociedade: lembranças de velhos. São Paulo: TA Queiroz.

Bosi, E. (1993). A pesquisa em memória social. Psicologia USP, $4(1 / 2), 277-284$.

Bourdieu, P. (1997). Compreender. Em P. Bourdieu (Org.), A miséria do mundo (pp. 693-713). Petrópolis, RJ: Vozes.

Campos, M. M. (1984). O ensino obrigatório e as crianças fora da escola: reavaliação do problema pela população de dois bairros da cidade de São Paulo. São Paulo: FCC/DPE.

Campos, M. M., \& Goldenstein, M. S. (1981). O ensino obrigatório e as crianças fora da escola: um estudo da população de sete a catorze anos excluída da escola na cidade de São Paulo. Projeto Educação e Desenvolvimento, Subprojeto 5. São Paulo: FCC/ DPE.

Charlot, B. (2000). Da relação com o saber: elementos para uma teoria. Porto Alegre: Artmed.

Collares, C. A. L., \& Moysés, M. A. A. (1996). Preconceitos no cotidiano escolar: ensino e medicalização. Campinas, SP: Cortez/Unicamp.

Cruz, S. H. V. (1997). Representação de escola e trajetória escolar. Psicologia USP, 8(1), 91-111.

Gonçalves Filho, J. M. (2003). Problemas de método em Psicologia Social: algumas notas sobre a humilhação política e o pesquisador participante. Em A. M. B. Bock (Org.), Psicologia e compromisso social (pp. 193-239). São Paulo: Cortez.

Goldenstein, M. S. (1986). A exclusão da escola de $1^{\circ}$ grau: a perspectiva dos excluídos. São Paulo: FCC.

Lahire, B. (1997). O sucesso escolar nos meios populares: as razões do improvável. São Paulo: Ática.

Oliveira, M. K. (1996). Escolarização e organização do pensamento. Revista Brasileira de Educação, (3), 97-102.

Oliveira, M. K. (2005). Pensar a educação: contribuições de Vygotsky. Em J. A. Castorina e cols., Piaget e Vygotsky: novas contribuições para o debate (pp. 51-83). São Paulo: Ática.

Paro, V. H. (1995). Por dentro da escola pública. São Paulo: Xamã.

Patto, M. H. S. (1990). A produção do fracasso escolar: histórias de submissão e rebeldia. São Paulo: TA Queiroz.

Portes, E. A. (2000). O trabalho escolar das famílias populares. Em M. A. Nogueira, G. Romanelli \& N. Zago (Orgs.), Família e escola: trajetórias de escolarização em camadas médias e populares (pp. 61-80). Petrópolis, RJ: Vozes.

Portes, E. A. (2001). Trajetórias escolares e vida acadêmica do estudante pobre da UFMG: um estudo a partir de cinco casos. Tese de doutorado, Faculdade de Educação, Universidade Federal de Minas Gerais, Belo Horizonte.

Rego, T. C. (1995). Vygotsky - uma perspectiva histórico-cultural da educação. Petrópolis, RJ: Vozes.

Rego, T. C. (2002). Configurações sociais e singularidades: o impacto da escola na constituição dos sujeitos. Em M. K. Oliveira, D. T. R. Souza \& T. C. Rego (Orgs.), Psicologia, educação e temáticas da vida contemporânea. São Paulo: Moderna.

Rochex, J.Y. (1995). Le sens de l' experience scolaire. Paris: PUF.

Sawaya, S. M. (1999). A leitura e a escrita como práticas culturais e o fracasso escolar das crianças de classes populares: uma contribuição crítica. Tese de Doutorado, Instituto de Psicologia, Universidade de São Paulo, São Paulo.

Setton, M. G. J. (1999). A divisão interna do campo universitário: uma tentativa de classificação. Revista brasileira de estudos pedagógicos, 80(196), 451-471.

Spósito, M. P. (1984). O povo vai à escola. São Paulo: Loyola.

Spósito, M. P. (1993). A ilusão fecunda: a luta por educação nos movimentos populares. São Paulo: Hucitec/Edusp.

Viana, M. J. B. (1998). Longevidade escolar em famílias de camadas populares: algumas condições de possibilidades. Tese de 
doutorado, Faculdade de Educação, Universidade Federal de Minas Gerais, Belo Horizonte.

Viana, M. J. B. (2000). Longevidade escolar em famílias de camadas populares - algumas condições de possibilidade. Em M. A. Nogueira, G. Romanelli \& N. Zago (Orgs.), Família e escola: trajetórias de escolarização em camadas médias e populares (pp. 45-60). Petrópolis, RJ: Vozes.
Vigotski, L. S. (1984). A formação social da mente. São Paulo: Martins Fontes.

\section{Sobre as autoras}

Débora Cristina Piotto (dcpiotto@usp.br)

Faculdade de Filosofia, Ciências e Letras de Ribeirão Preto / USP.

Renata Oliveira Alves (renataluacheia@yahoo.com.br)

Faculdade de Filosofia, Ciências e Letras de Ribeirão Preto / USP.

\section{Endereço para correspondência:}

Av. Bandeirantes, 3.900

Cidade Universitária

Dep. de Psicologia e Educação - FFCLRP / USP

CEP: $14040-901$

Ribeirão Preto - São Paulo 